\title{
Uma intervenção pedagógica no contexto de uma biblioteca escolar: delineando caminhos para transformar um ambiente estático em espaço dinâmico
}

\author{
A pedagogical intervention in the context of a school library: outlining ways to transform \\ static environments into dynamic
}

\author{
Lucas Veras de Andrade \\ Licenciado em Pedagogia. Bacharel em Biblioteconomia. Especialista em Supervisão Educacional. \\ Docente da rede Municipal de Teresina - PI, Brasil. \\ E-mail: lukkandrade18@hotmail.com \\ Michel de Oliveira Machado \\ Professor das Séries Iniciais do Ensino Fundamental da Prefeitura de São Paulo. \\ E-mail: michel.machado@bol.com.br
}

\begin{abstract}
Resumo
Relata-se uma intervenção no contexto de uma biblioteca escolar de uma escola municipal de Teresina (PI) que teve o intuito de torná-la um espaço de ação ativa. No percurso interventivo, a análise teve como parâmetros os aspectos: arquitetônicos que no decorrer do processo foi denominado de organizacional, biblioteconômicos e pedagógico. Destes apenas o primeiro se mostrou satisfatório para o desenvolvimento de atividades fins do ambiente do qual discutimos. O segundo pela ausência de um profissional no espaço apresentou fragilidade na recuperação da informação devido à inexistência de um sistema de classificação e sinalização. O pedagógico a nosso ver é o que mais inviabilizava o desenvolvimento de atividades, uma vez que a biblioteca nesse sentido não se configurava articulada com o projeto educacional da instituição em análise. Com a intervenção os aspectos mencionados foram reconfigurados e ações nesse sentido foram sugeridas, no entanto não estaremos certo dos resultados, pois para consolidar estes a escola precisa concretizar as ações pensadas e descritas no relato. A dúvida restará, no entanto, demos o passo inicial delineando estratégias para ressignificar um ambiente estático como demonstrado no diagnóstico, tranformando-o em um espaço atrativo para as crianças a partir da classificação em cores e uma nova reconfiguração espacial do ambiente. Dessa forma, esperamos que o processo interventivo contribua para a melhoria educacional da escola na medida em que possibilitamos condições mínimas para a formação de leitores.
\end{abstract}

Palavras-chave: Biblioteca Escolar. Escola Professora Alda Rodrigues Neiva. Classificação em Cores. Atividades Pedagógicas em Bibliotecas Escolares.

\begin{abstract}
Reports-if an intervention in the context of a school library of a municipal school of Teresina (PI) that had the intention to make it an area of active action. In the course of intervention analysis had as parameters: architectural aspects which in the process was called biblioteconômicos and pedagogical, organizational. Of these only the first proved to be satisfactory for the purposes of the environment activities which we discussed. The second by the absence of a professional space presented fragility in the recovery of information in the absence of a classification system and signage. The teaching in our view is what precluded the development of activities, since the library accordingly not allegedly linked to the educational project of the institution in question. With the intervention aspects mentioned were reconfigured and actions in that direction were suggested, however we are not sure of the results, is to consolidate these school needs to realize the actions designed and described in the report. The question remains, however, gave the initial step outlining strategies to resign a static environment as demonstrated in the diagnosis, turning it into an attractive space for children from the colour classification and a new reconfiguration of space environment. In this way, we hope that the process of intervention contributes to the educational improvement of the school to the extent that we provide minimum conditions for the formation of readers.
\end{abstract}

Keywords: School Library. School Teacher Alda Rodrigues Neiva. Color classification. Pedagogical activities in school libraries. 


\section{Introdução}

Ainda hoje encontramos realidades em que a biblioteca escolar se encontra distante dos sujeitos escolares por inúmeras motivações, mas principalmente pela falta de articulação desta com o projeto educacional escolar. No entanto, pensar neste espaço é concebê-lo como um forte componente educacional que contribui para potencializar diversas habilidades e competências no alunado e nos diversos atores que ela atende. Mais que isso, é imaginar um mundo de descobertas, aprendizagens e principalmente de possibilidades.

Ao analisarmos o papel das bibliotecas escolares na contemporaneidade devemos percebê-las e inserí-las na conjuntura da sociedade da informação e do conhecimento. Nesta a biblioteca é vista com um espaço de promoção de aprendizagens e formação de indivíduos críticos/reflexivos capazes de gerenciarem informações de forma autônoma e responsável mediante práticas leitoras e culturais diversas.

Desse modo, devemos adaptar nossas crianças e jovens para esta sociedade emergente, possibilitando condições favoráveis como: espaço físico adequado, coleções atualizadas e desenvolvidas mediante critérios racionais, práticas culturais e principalmente banir do imaginário dos responsáveis por gerir estes ambientes o "achismo" de que basta um indivíduo a sua frente para a guarda e organização do acervo bibliográfico para que ela alcance sua função. Concepções como esta dão a biblioteca escolar "apenas a finalidade de preservação e não movimentação contínua das palavras e das idéias", como afirma Fragoso (2013, p.12).

Partindo da concepção de biblioteca no contexto da sociedade do conhecimento, buscaremos relatar uma experiência vivenciada no contexto da biblioteca da Escola Municipal Professora Alda Rodrigues Neiva, situada na cidade de Teresina (PI), mediante uma intervenção pedagógica que buscou oportunizar condições para se concretizar a competência informacional aos escolares vinculados a mesma. O intuito foi modificar a realidade da biblioteca escolar que se mostrava pouca atrativa para os alunos e comunidade e transformá-la em um ambiente motivante de modo que todos se sintam atraídos por ela.

Assim, objetivamos com nossa intervenção: a) Fazer com que o espaço da biblioteca esteja inserido ao processo educacional, sendo pensado a partir do currículo, b) Permitir de forma lúdica através da classificação em cores a construção da competência informacional infantil, c) Desenvolver atividades no espaço da biblioteca que promovam o desenvolvimento crítico e o gosto literário dos alunos e por fim, d) Possibilitar mediante as atividades 
anteriormente citadas, o entendimento nos escolares que a biblioteca é por excelência um local prazeroso de se frequentar, refutando a ideia desenvolvida por más práticas de alguns no imaginário do alunado que o ambiente da biblioteca é um espaço de castigo.

Dessa forma, o relato está organizado em seções onde inicialmente pontuamos o porquê de planejarmos e desenvolvermos a intervenção. Na segunda seção apresentamos o diagnóstico situacional, onde analisamos o funcionamento, estrutura e organização de três aspectos sendo, estes: arquitetônico, biblioteconômico e pedagógico da biblioteca escolar. A terceira contempla o delineamento metodológico, ou seja, descreve o percurso empreendido no construto da intervenção. Logo após, temos o processo prático onde demonstramos as ações empreendidas em lócus e por último tecemos algumas considerações onde retomamos a discussão sobre a importância da biblioteca escolar e o sentido da ação empreendida no espaço da biblioteca da escola.

\section{Diagnóstico Situacional da Biblioteca da Escola Municipal Professora Alda Rodrigues Neiva}

Nosso diagnóstico foi pensado e desenvolvido a partir dos preceitos de Neves e Ramos (2010). As autoras pontuam dois aspectos em análises de bibliotecas escolares, sendo estes: arquitetônicos e biblioteconômicos. O primeiro diz respeito organização do espaço e o segundo compete ao fazer bibliotecário, como por exemplo, classificação dos títulos, desenvolvimento de coleção, entre outros. Juntamente a estes pontuamos o aspecto pedagógico.

Entendemos por aspectos pedagógicos as estratégias que o mediador ou o profissional responsável pela biblioteca realiza para provocar a curiosidade, a significação e a capacidade de reflexão dos discentes a partir das informações obtidas mediante os materiais resguardados na biblioteca. Ainda neste aspecto estão inclusos o trabalho com projetos e atividades que fundamentam ou corroboram com o ensino e aprendizagem do alunado em sala de aula. Dessa forma, a seguir mediante nosso diagnóstico evidenciaremos cada um destes aspectos. 


\section{Aspectos Arquitetônicos}

A biblioteca em análise localiza-se em uma sala nas dependências da escola supracitada. Segundo nossa percepção a mesma não se apresenta como um local agradável e passível de desenvolvimento de atividades por várias questões.

A primeira, porque a mesma se evidenciou como um depósito, principalmente para os materiais utilizados nas aulas de educação física. O segundo pela ausência parcial de mobiliário, embora presente no espaço, a quantidade se mostrou insuficiente para atender as demandas e o desenvolvimento de atividades com grupos de alunos, mesmo que pequeno. Ainda em relação ao mobiliário, o mesmo não se evidenciou como ideal pelo fato de os mesmos não terem o tamanho adequado para a faixa etária da maior parte da clientela atendida, ou seja, crianças de 6 a 10 anos.

No que tange ventilação e temperatura, o espaço conta com duas formas: a natural e a artificial. A título de informação, a literatura especializada em conservação pontua estes elementos como fundamentais na estrutura arquitetônica de espaços como bibliotecas escolares, já que o acervo é sensível a mudanças súbitas de temperatura e a umidade excessiva. A ocorrência desses fatores contribui para o surgimento de agentes biológicos como fungos e bactérias, além de colaborarem para minimizar a vida útil de materiais como o papel (totalidade do acervo da biblioteca em questão). Ainda sobre a temperatura, especialistas na área recomendam que a mesma fique entre $19^{\circ}$ e $23^{\circ} \mathrm{C}$ e a umidade em torno de $45 \%$ a $50 \%$, evitando-se de todas as formas as oscilações de $3^{\circ} \mathrm{C}$ de temperatura e $10 \%$ de umidade relativa (CASSERES, 2000, p.15).

Outro elemento pontuado em nossa análise é a iluminação. Em relação a este Casseres (2000, p. 15) evidencia que "Toda fonte de luz, seja ela natural ou artificial, emite radiação nociva aos materiais de acervos, provocando consideráveis danos através da oxidação". Assim como na temperatura, este aspecto apresenta as duas formas citadas anteriormente, tanto na forma natural (solar) como artificial (lâmpadas fluorescentes), entretanto a artificial prevalece, o que é favorável a conservação do acervo, pois esta se torna mais fria, além de ser de fácil manutenção pelo seu custo baixo.

Outros elementos também foram analisados como a acústica, pisos e paredes, acessibilidade aos portadores de deficiências e a segurança do espaço. Destes, apenas a acústica e o último aspecto mencionado necessitam de ponderações emergenciais. Mesmo 
sendo forrado como recomenda a literatura especializada, o espaço apresenta ruídos vindos do exterior do ambiente, principalmente nos horários em que a educação física dos estudantes está sendo desenvolvida. Já em relação à segurança, as estantes estavam passíveis de virarem em função de estarem repletas de livros.

Pelo analisado e as reflexões feitas com base em nossas observações, constatamos que o espaço apresenta condições arquitetônicas de utilização e desenvolvimento de atividades que cumpram a finalidade de uma biblioteca escolar, cabendo a necessidade de uma reorganização e compra de mobiliário, acervo e transferência dos materiais mencionados ao iniciarmos este tópico para outros locais para devido armazenamento.

\section{Aspectos Biblioteconômicos}

O espaço não conta com um profissional seja ele, especializado ou não para garantir a eficácia do funcionamento e que venha a potencializar as finalidades da biblioteca na escola, ficando este aberto aos alunos sem sistematização de atividades. Esse aspecto segundo nossa perspectiva é o que mais compromete e demonstra fragilidades, uma vez que o espaço sozinho e sem orientação aos usuários, os mesmos o utilizam da forma como desejarem. Isto implica em exemplares perdidos, danificados, na inviabilidade de recuperação da informação pela desorganização, além de um espaço nessas condições passar uma concepção errônea para o alunado e comprometer o entendimento no que tange ao aspecto conceitual e da usabilidade nas diversas tipologias de bibliotecas que ele venha a usufruir no futuro.

Diante da situação acima, todos os aspectos biblioteconômicos ficam comprometidos. Em relação ao acervo, observou-se uma diversidade de materiais. Detectou-se que muitos dicionários e enciclopédias estão obsoletos, pois muitas palavras contidas nestes estão escritas em desuso atualmente. Ainda com relação ao acervo, o mesmo não possuía nenhuma sistematização organizacional, ou seja, não possuía nenhum tipo de processamento técnico

Um percentual grande da coleção da biblioteca se mostrou sujo e mal conservado, com ausência de capas e títulos faltando páginas. O acervo é na sua maioria composto de livros enviados pela secretaria municipal de educação de Teresina/PI mediante PNLD (Programa Nacional do Livro Didático) e por doações de uma grande escola da rede privada da cidade, que quando doados são inseridos na coleção sem prévia seleção. 
Podemos afirmar segundo entrevista com a ex-diretora da escola que o acervo se constitui de forma aleatória, sem critérios sólidos e racionais, e diante disto se evidencia a necessidade de um projeto voltado para uma política de desenvolvimento da coleção na biblioteca. Na perspectiva Vergueiro $(1995,2010)$ a política de desenvolvimento de coleção é um instrumento formal que estabelece critérios que garantem o desenvolvimento e manutenção da coleção de forma racional. A política se faz necessária uma vez que é por meio de seus critérios que se garante a adequação das demandas do acervo à comunidade na qual a biblioteca atende, ou seja, a coleção deve ser desenvolvida levando em consideração sugestões da clientela atendida, necessidades específicas de trabalho dos docentes e acima de tudo ir ao encontro das aspirações do contexto onde a biblioteca estar inserida.

Dentre toda a coleção analisada, os livros infanto juvenis são os que se evidenciam em maior quantidade, e dentre os diversos materiais encontrados são os mais solicitados, entretanto, apresentaram-se misturados, pelo fato de a biblioteca não possuir uma diferenciação tipológica para cada material. Estes estão mal localizados e muitas vezes guardados em lugares muitos altos, o que dificulta o acesso e uso pelo público usuário. $\mathrm{Na}$ mesma situação encontram-se os periódicos, em nossa análise diante destes, constatou-se que maior parte são voltados para a formação de professores e em suma, os classificamos como bons, pois podem ser utilizados no aperfeiçoamento das competências docentes, entretanto em conversa informal com alguns professores, a maioria destes os desconhecem pela falta de divulgação, pela dificuldade de acesso e desorganização dos materiais na biblioteca.

\section{Aspectos Pedagógicos desenvolvidos na biblioteca}

Para demonstrarmos este aspecto, fez-se necessário entrevistar a ex-gestora da instituição, hoje removida da mesma. A escolha por esta se deu pelo fato de a mesma estar em serviço desde a fundação da escola e ser ela por isso, a pessoa mais indicada ao fornecimento de informações que nos permitisse compreender as motivações que justificassem a situação na qual nos deparamos e mencionamos na análise dos aspectos acima elencados.

Nesse sentido e na perspectiva da respondente, nos treze anos de funcionamento da escola, a biblioteca sempre que possível contou com atividades. Chamou-nos atenção quando a mesma pontuou "sempre quando possível". A respeito disso quando instigada, a mesma relatou que seu posicionamento se estabelece desta forma, porque a instituição educacional 
necessitou nesse percurso de treze anos do espaço para o desenvolvimento de outras atividades, que segundo a mesma eram de maior importância, como exemplo destas, foi citado o reforço escolar.

Ainda com relação às atividades, estas quando desenvolvidas no lócus em discussão ficava sob a incumbência de uma professora responsável que foi lotada no ambiente da biblioteca escolar em função do tempo de serviço e estar em aguardo da aposentadoria que se efetivou em 2011. Segundo o discurso a docente desenvolvia atividades de leitura e fazia um trabalho rigoroso em relação ao empréstimo, principalmente em cobrar dos discentes a devolução dos materiais emprestados.

Quase três anos se passaram e pela nossa experiência inseridos no contexto da instituição como docentes, pouco ou nada se percebeu de melhoria no sentido do uso, desenvolvimento e implementação de atividades no ambiente em questão, daí surgiu à vontade em nós de mudar tal realidade.

A escola apresenta ainda um projeto pedagógico denominado de biblioteca ativa. Entretanto, este segundo a nossa percepção não se liga diretamente ao desenvolvimento de atividades ao contexto da biblioteca escolar, a não ser pelo nome. Neste os alunos de acordo com o gênero textual trabalhado em sala pelos docentes, dramatizam histórias a partir de ensaios na própria sala de aula no pátio da escola para os demais alunos da instituição.

Com base no exposto, inferimos que o ambiente da biblioteca da escola não tem sido maximizado em toda a sua potencialidade, não sendo organizado de modo a dispor de atividades que contribuam ao estímulo da consciência cultural, promoção da leitura e os serviços de uma biblioteca escolar e principalmente ao apoio a aprendizagem. 


\section{Trilha Metodológica: o caminho percorrido...}

Dividimos o percurso metodológico em dois momentos: o primeiro direcionado a escolha dos métodos de coleta dos dados para elaboração do diagnóstico, assim como para as análises de forma qualitativa e o segundo referente à atividade prática. Desse modo, no primeiro momento nos utilizamos da observação assistemática que pode ser entendida como um tipo de observação que tem por objetivo registrar os fatos sem que o pesquisador se utilize de técnicas especiais, ou seja, sem o controle previamente elaborado para análise do ambiente. Vianna (2003, p. 26-27) em relação a esse tipo de método afirma que:

[...] é com bastante frequência usada como técnica exploratória, em que o observador tenta restringir o campo de suas observações para, mais tarde, delimitar suas atividades, modificando, às vezes, os seus objetivos iniciais, ou determinando com mais segurança e precisão o conteúdo das suas observações e proceder às mudanças que se fizerem necessárias no planejamento inicial.

A observação assistemática também é conhecida como não estruturada. Outro procedimento utilizado foi a entrevista do tipo não estruturada na forma em que esta esteve centrada na problemática da má utilização do espaço da biblioteca escolar. Escolhemos esta forma por entendemos que muitas eram as possibilidades de que a narração proferida pela exdiretora, ou seja, nossa entrevistada nos guiasse para o entendimento que proporcionou a situação encontrada em nosso diagnóstico.

O segundo momento foi dividido em três eixos mediante os aspectos visados na análise diagnóstica. $\mathrm{O}$ único aspecto reconsiderado em sentido conceitual foi à questão arquitetônica, já que em nosso entendimento esta nomenclatura denota muito o aspecto da estrutura predial em si e a necessidade que mais demanda mudança no espaço seria em nível de aquisição de mobiliário e modificações a respeito da localização de algumas estantes. Assim decidimos mudar a nomenclatura arquitetônica por composicional. Os outros eixos permaneceram com a mesma nomenclatura do diagnóstico.

Desse modo, temos por ordem de execução: eixo biblioteconômico, eixo pedagógico e por último o composicional. Assim no primeiro eixo permanecemos por três semanas em busca de leituras e aprofundamento teórico na área de biblioteconomia, para que pudéssemos pensar e desenvolver atividades condizentes e que estimulassem a competência informacional em crianças. Neste eixo, escolhemos a forma de classificação bibliográfica, a sinalização das estantes, elaboração da política de desenvolvimento da coleção e a forma de empréstimo. 
Em relação ao eixo pedagógico, este tem o intuito de aliar o trabalho dos docentes ao contexto da biblioteca mediante atividades lúdicas e projetos pedagógicos, assim como a usabilidade do ambiente visando à mediação e o desenvolvimento da competência informacional da clientela de usuários na qual o espaço presta seus serviços.

No terceiro eixo a principal mudança a ser empreendida era a questão da compra do mobiliário para atender um público maior no que compete ao desenvolvimento de atividades no espaço. Como a questão em pauta necessitava de recursos financeiros, tivemos que recorrer a negociações com a ex-diretoria da escola. Após uma explanação do objetivo da intervenção e a exposição da nossa parte das necessidades de mudanças no ambiente da biblioteca, a mesma se mostrou muito sensível, o que denota o entendimento pela mesma que o espaço a ser intervido é um requisito essencial para o desenvolvimento de algumas competências e habilidades nos alunos e mais que isso, é uma das condições reais para a aquisição da leitura e alfabetização, uma das grandes problemáticas e uma preocupação da escola. Dessa maneira, logo a mesma destinou recursos do Plano de dinheiro direto na escola (PDDE) para aquisição de qualquer material que necessitássemos. O PDDE é um recurso anual depositado na conta do Conselho Escolar, no caso da escola pública (Objeto deste estudo) e visa o melhoramento tanto físico como pedagógico da escola, cujas prioridades são mapeadas com a comunidade escolar, tendo como principal objetivo a melhoria da aprendizagem dos discentes.

Após a liberação dos recursos foram feitas algumas pesquisas de preços, analisamos a qualidade dos produtos em alguns estabelecimentos de vendas, fez-se a escolha daqueles que respondiam as necessidades do projeto, comprando-se mesas, cadeiras, estantes, assim como livros infantis nos diversos gêneros textuais, mediante lista de desiderata elaborada após análise do acervo. A seguir detalhar-se-á as atividades empreendidas. 


\title{
Processo Interventivo: mudando a realidade encontrada
}

\author{
Atividades - Eixo Biblioteconômico
}

Como já mencionado no diagnóstico, o acervo é demonstrado com deficiências de diversas naturezas. Nesse sentido, nossa primeira atitude no espaço foi em relação ao mesmo e sua organização. Dessa forma, retiramos todos os títulos das estantes e os limpamos. Logo após, mediante catalogação na fonte, que pode ser entendida como a classificação mediante a ficha catalográfica, os separamos pelos gêneros textuais, assim como também em disciplinas e periódicos. A atitude de classificarmos os exemplares a partir dos gêneros textuais se deu por entendermos que dessa forma estaríamos ajudando os discentes a vivenciarem com mais praticidade e rapidez o gênero estudado em sala de aula a partir da usabilidade do acervo, assim como os docentes, melhorando a qualidade dos planejamentos e, por conseguinte as aulas, uma vez que as diretrizes educacionais do município de Teresina para o ensino fundamental pautam a ação docente a partir da explanação dos gêneros textuais na perspectiva do letramento, ou seja, do uso dos gêneros no meio social.

Outra atividade empreendida em relação ao acervo foi à classificação em cores. A escolha por este tipo de código se deu pelo fato de crermos que é a metodologia que mais se adequa ao público escolar em nível fundamental menor e "é um fator importantíssimo na recuperação da informação por construir um elo entre a linguagem visual e a busca do material nas estantes" (PINHEIRO, 2009, p. 166). Em relação à classificação em cores, tentamos utilizar as mais vibrantes cores com o intuito de chamar atenção dos alunos e permitir de forma lúdica que eles viajem ao mundo ímpar que as leituras e as histórias proporcionam.

Optamos por não classificar os livros didáticos e os periódicos em cores por duas vertentes: a primeira pela quantidade de ambos não demandar um espaço em quantidade, podendo uma sinalização mais simples atender a necessidade tanto de recuperação quanto de visualização e a segunda pela fácil compreensão destes.

Como forma de demonstrar e facilitar o entendimento do que acima explanamos, a seguir apresentaremos o quadro 1, que consta a classificação em cores que elaboramos e a respectiva organização do acervo. Dessa maneira temos: 
QUADRO 1: Organização do Acervo e Classificação em Cores

\begin{tabular}{|c|c|c|c|c|}
\hline $\begin{array}{c}\text { Grupo 1 } \\
\text { Coleção do Gênero Textual }\end{array}$ & $\begin{array}{c}\text { Classificação por } \\
\text { Cor }\end{array}$ & Total & $\begin{array}{c}\text { Grupo 2 } \\
\text { Coleção por Disciplina }\end{array}$ & Total \\
\hline Acervo de Referência & & 107 & \multirow{4}{*}{ Língua Portuguesa } & \multirow{4}{*}{153} \\
\hline Antologia & & 2 & & \\
\hline Autobiografia/Biografia* & & 3 & & \\
\hline Canção/ Música ${ }^{1}$ * & & 1 & & \\
\hline Carta/Bilhete* & & 3 & \multirow{3}{*}{ Matemática } & \multirow{3}{*}{135} \\
\hline Cinema & & 1 & & \\
\hline Contos & & 129 & & \\
\hline Crônica & & 1 & \multirow{3}{*}{ História } & \multirow{3}{*}{155} \\
\hline Fábula & & 6 & & \\
\hline Ficção & & 9 & & \\
\hline Folclore $^{2}$ & & 58 & \multirow{2}{*}{ Geografia } & \multirow{2}{*}{106} \\
\hline Literatura Infanto Juvenil & & 294 & & \\
\hline Literatura Piauiense & & 38 & \multirow{2}{*}{ Ciências } & \multirow{2}{*}{87} \\
\hline História em Quadrinhos & & 8 & & \\
\hline Novela & & 52 & \multirow{3}{*}{ Inglês } & \multirow{3}{*}{5} \\
\hline Poesia/Poema* & & 58 & & \\
\hline Reportagem/Notícia* & & 1 & & \\
\hline Romance & & 9 & \multirow{3}{*}{ Espanhol } & \multirow{2}{*}{1} \\
\hline Teatro & & 16 & & \\
\hline \multirow[t]{2}{*}{ Trava-Língua } & & 1 & & \\
\hline & Total & 796 & Total & 642 \\
\hline
\end{tabular}

Fonte: Elaboração dos Autores.

*Pela semelhança teórica, alguns gêneros foram aglutinados para melhor recuperação da informação pelo usuário.

${ }^{1}$ Livros de Composições, História e Crítica.

${ }^{2}$ Sinalização classificatória que compôs todas as manifestações folclóricas encontradas no acervo: Ex. lendas, costumes, cordel.

Em relação aos periódicos foram encontrados 46 (quarenta e seis) tipos que foram organizados pelos respectivos títulos. Diante destes, tivemos a preocupação de darmos aos mesmos um tratamento diferenciado, colocando em lugar estratégico no ambiente da biblioteca para que o alunado reflita e perceba que o periódico é um material diferenciado diante dos demais, sendo uns diários, outros semanais e mensais, ou seja, tem uma periodicidade de publicação e que apresentam informação em "caráter instantâneo e alguns momentos voláteis, a exemplo o jornal", diferente dos livros. Lógico que a capacidade de entendimento que aqui defendemos diante destes pelos alunos é processual, ou seja, ocorrerá na medida em que se desenvolva uma cultura do uso da biblioteca e dos materiais, já que 
muitos alunos relatam em conversa informal desconhecer o espaço em questão. Assim, a seguir demonstraremos por meio dos títulos os periódicos disponíveis no acervo.

QUADRO 2: Periódicos

\begin{tabular}{|c|c|c|c|}
\hline \multicolumn{4}{|c|}{ Grupo 3 - Coleção de Periódicos } \\
\hline Título & Total & Título & Total \\
\hline Carta Fundamental & 11 & Pátio Educação Infantil & 12 \\
\hline Ciência Hoje & 183 & Presença Pedagógica & 5 \\
\hline Cidade Nova & 7 & Pro Teste & 18 \\
\hline Cidade Verde & 1 & Projetos Escolares: educação infantil & 2 \\
\hline Ciência Tecnológica \& Inovação & 1 & Quatro Rodas & 1 \\
\hline Criativa & 1 & Revista Aprende Brasil & 1 \\
\hline Discutindo Literatura & 1 & Revista Cláudia & 1 \\
\hline Discutindo Geografia & 1 & Revista Dinheiro e Direito & 1 \\
\hline Exame & 2 & Revista do Brasil & 3 \\
\hline $\begin{array}{c}\text { Guia Prático para Professores do Ensino } \\
\text { Fundamental I }\end{array}$ & 1 & Revista do Professor & 3 \\
\hline Informativo MEC & 12 & Revista do Tribunal de Justiça do Piaú & 1 \\
\hline Istoé & 3 & Revista Gestão em Rede & 1 \\
\hline Jornal da Musculação e Fitness & 1 & Revista Inclusão & 2 \\
\hline Leituras & 2 & Revista Leya na escola & 1 \\
\hline Manequim & 2 & Revista Nordeste Vinte e Um & 10 \\
\hline Nova Escola & 56 & TV Escola & 2 \\
\hline Revista Atividades e Experiências & 1 & Veja & 58 \\
\hline Carta na Escola & 1 & Revista Língua Portuguesa & 1 \\
\hline Contigo & 1 & Boletim Técnico Fundescola & 3 \\
\hline Revista Força Jovem & 1 & Revista Diocesano & 2 \\
\hline Revista Viagem & 1 & Revista Mundo Jovem & 1 \\
\hline Revista Viver Mais & 1 & Revista Saúde & 1 \\
\hline Revista Especial Sambão & 2 & De repente & 1 \\
\hline
\end{tabular}

Fonte: Elaboração dos Autores.

A segunda atividade desenvolvida foi à elaboração da política de desenvolvimento da coleção da biblioteca da escola. Nesta descrevemos o perfil da coleção e a partir disto criamos alguns critérios em relação à aquisição e descarte. Outro aspecto proposto na política foi a padronização mediante confecção de capas da cor vermelha de papel cartão, revestido de fita adesiva dos materiais restaurados, principalmente aqueles que por conta do desgaste se apresentam sem capa. A proposta é um encaminhamento meramente administrativo que se respalda em se poder avaliar de forma mais fácil no decorrer do tempo a deteriorização desses materiais, que já se encontram gastos e possível encaminhamento de forma prática para o desbastamento e possível descarte definitivo da coleção. Lembrando que aqui só apresentamos alguns aspectos da política desenvolvida para biblioteca da escola e que esta quando desenvolvida e aplicada varia de acordo com a realidade e circunstâncias que se apresentam em cada ambiente. 
A seguir apresentaremos as atividades do eixo pedagógico pensados para a biblioteca, sendo este a nosso ver o elemento chave para o bom funcionamento e a construção imagética de forma positiva do espaço que discutimos.

\section{Atividades - Eixo Pedagógico}

Pelo discurso de nossa interlocutora na entrevista, o aspecto pedagógico no contexto da biblioteca em análise demonstrou-se sem ações efetivas que pudessem potencializar o espaço e aliá-lo ao contexto da sala de aula e principalmente com a aprendizagem dos alunos. Nesse sentido, a primeira atividade pensada foi a respeito da organização da coleção na perspectiva da mediação pedagógica informacional e em seguinte pensar em atividades que o contexto da biblioteca escolar estivesse mais próximo da sala de aula, na aprendizagem e dos alunos de um modo geral.

Em relação à organização da coleção, pontuamos este aspecto no eixo biblioteconômico sob o enfoque técnico, e expomos o passo a passo interventivo. A seguir teceremos apenas de forma breve algumas considerações a respeito da importância da organização do acervo e de um sistema de classificação que possibilite esta, que no caso de nossa intervenção escolhemos a classificação em cores.

Acreditamos que ambos os aspectos acima mencionados quando orientado na perspectiva pedagógica e com mediação contribuem para desenvolver no alunado a autonomia necessária para a construção da competência informacional, competência esta que insere os escolares a sociedade da informação. Nossa afirmação é respaldada nas palavras de Aguiar (2012, p 31), quando diz que:

\footnotetext{
Para adaptar as crianças à Sociedade da Informação e do Conhecimento, faz-se necessário oferecer a elas recursos informacionais que as introduzam neste mundo em constante evolução e transformação. Mais que habilidades tecnológicas, é imprescindível estabelecer condições para que este público desenvolva a assimilação de conteúdos e estabeleça uma consciência crítica diante da grande quantidade de informações disponíveis.
}

Estabelecendo conexão ao que explanamos e o discurso da autora, pontuamos a inserção da criança e mais que isso, a sua orientação para o uso da informação organizada como um fator imprescindível para a autonomia na qual mencionamos logo ao iniciarmos a discussão. Conforme declara a International Federation of Libraries Associations (IFLA) 
(2005) é tarefa da biblioteca escolar oferecer ideias e/ou informações capazes de tornar seus usuários capazes ou como afirma Aguiar (2012, p 31) "bem sucedidos" ao contexto atual da informação, denominado de sociedade do conhecimento.

A classificação em cores é uma forma de sinalização organizacional que permite e incentiva a autonomia mirim pelo seu caráter lúdico e estético que desperta a curiosidade por meio do seu uso e permite que o aluno internalize a concepção de que o ambiente de uma biblioteca escolar é um universo com inúmeras atividades, o que propicia aos mesmos várias habilidades e competências que os tornam aptos a rotina e ao convívio com outras modalidades de bibliotecas que eles se deparem no percurso de suas vidas, mas para isso é necessário a inserção dos alunos desde cedo no universo das bibliotecas, porque só assim eles compreenderão a funcionalidade destas.

Uma biblioteca bem organizada, sendo um ambiente acolhedor, com uma sinalização atrativa e compreendida pelo seu público, chama atenção e convida estes ao convívio e visitação constante, principalmente quando se trata de crianças. Em relação à sinalização Silva e Silva (2012, p. 10) afirmam que "a sinalização seja qual for, implica em um convite [...], oferecendo e estimulando o usuário múltiplos subsídios de acesso, uso e apropriação da informação". Uma vez apresentado o caráter educacional que os componentes que apresentamos podem propiciar aos discentes, imaginamos também ser possível pensar na mediação da informação como uma prática pedagógica no contexto da biblioteca através de atividades, já que esta é um centro informacional e sua atuação depende de práticas informativo-pedagógicas. Pensando nisso, sugerimos algumas atividades para os professores da escola de modo que estas permitissem a ligação do contexto em questão com conteúdos e a sala de aula, uma vez que a biblioteca tem um de seus objetivos fundantes respaldar a prática dos docentes.

A primeira atividade empreendida foi a sugestão da construção de um quadro mural onde por disponibilidade dos professores ficou estabelecido um horário na carga horária para cada um levar sua turma para deleite de leitura inicialmente. Pontuamos inicialmente, porque acreditamos que no decorrer do ano e na trajetória do ambiente analisado serão pensadas outras ações, uma vez que a postura da direção da escola e dos professores frente nossas recomendações se mostrou favorável, fazendo-nos acreditar que para eles o ambiente da biblioteca é um espaço que integra, transforma e enriquece a aprendizagem dos alunos. 
Uma vez aberto o espaço para o desenvolvimento de ações, sugerimos algumas atividades para os professores de caráter lúdico que podem ser empreendidas no espaço e que certamente chamará a atenção dos discentes e principalmente dará a biblioteca o caráter vivo que este espaço deve ter em instituições escolares, além de modificar o olhar do aluno diante desta frente à realidade anteriormente mencionada. Desse modo, temos:

QUADRO 3: Atividades

\begin{tabular}{|c|c|}
\hline Atividades & Descrição \\
\hline Maleta da Leitura & $\begin{array}{l}\text { Sabemos que por mais que nos esforcemos ainda existirão alunos que se } \\
\text { manterão distantes dos livros e, por conseguinte da leitura. Esta atividade foi } \\
\text { pensada exatamente para estes, já que a maleta tem o caráter volante, ou seja, ela } \\
\text { será enviada da biblioteca diretamente para as salas de aulas em dia previsto ou } \\
\text { não. A proposta da maleta visa mover e estimular principalmente os alunos que } \\
\text { mencionamos, e todos de modo geral a adentrarem no universo encantador e } \\
\text { fantástico das histórias dos livros. }\end{array}$ \\
\hline $\begin{array}{l}\text { Tecendo ideias, } \\
\text { construindo textos }\end{array}$ & $\begin{array}{l}\text { Para esta atividade será necessário uma caixa de porte pequeno a médio (que } \\
\text { pode ser personalizada para chamar mais atenção dos alunos) e o recorte de } \\
\text { várias figuras que ficarão resguardadas no interior da caixa. A ideia é de no } \\
\text { ambiente da biblioteca seja construído textos a partir de figuras. Um aluno ou } \\
\text { vários alunos serão convocados a retirar as referidas figuras de dentro da caixa } \\
\text { da imaginação e a partir destas o enredo da história será construído. A partir } \\
\text { disso, cada aluno desenvolverá um texto. O interessante é que todos os alunos } \\
\text { terão os mesmos condicionantes e elementos para compor o texto, entretanto, } \\
\text { como cada um age e senti de forma singular, várias serão as possibilidades de } \\
\text { histórias inventadas. Atividades como esta além de serem essenciais para o } \\
\text { processo de alfabetização (período em que se encontram os alunos da escola) } \\
\text { pelo seu caráter lúdico, desenvolvem a imaginação e criatividade dos alunos. } \\
\text { Esta atividade pode ser trabalhada com todos os gêneros textuais, exceto em } \\
\text { alguns que necessitam algumas alterações. }\end{array}$ \\
\hline Proseando & $\begin{array}{l}\text { Esta atividade foi pensada para ser iniciada na sexta-feira e finalizada na } \\
\text { segunda-feira. Nos minutos finais da aula de sexta-feira o professor levará sua } \\
\text { turma à biblioteca para que os discentes possam escolher obras e levar para } \\
\text { deleite de leitura em casa no final de semana via empréstimo. Na segunda-feira } \\
\text { nos momentos iniciais da aula sob orientação do professor os alunos farão uma } \\
\text { roda de conversa, onde vão historiar para os colegas a obra lida, recomendando } \\
\text { ou não a obra. Em caso de não recomendar, o aluno deverá expor para os } \\
\text { colegas as motivações para tal atitude. Lembrando que cabe ao professor } \\
\text { redirecionar o olhar deste aluno frente à obra não recomendada, tentando na } \\
\text { medida do possível realçar aspectos positivos a partir dos pontos elencados pelo } \\
\text { aluno. Daí a importância de os professores também serem leitores }\end{array}$ \\
\hline Historiando... & $\begin{array}{l}\text { É uma atividade pensada para a disciplina de história. O professor pode pedir } \\
\text { para os alunos pesquisarem variados livros e após leitura, o mesmo pode } \\
\text { explanar a temporalidade da obra mediante sua data de publicação ou de uma } \\
\text { data que esteja contextualizada na temática do livro, e a partir disso pode fazer } \\
\text { uma ligação contextual com algum momento histórico em que o Brasil } \\
\text { vivenciou ou outros países. O professor de literatura também pode se utilizar de } \\
\text { atividades como esta para tornar público informações sobre autores brasileiros e } \\
\text { da nossa realidade, ou seja, piauienses que ainda são desconhecidos por muitos, } \\
\text { alguns com representação nacional como Torquato Neto. }\end{array}$ \\
\hline $\begin{array}{l}\text { A tividades de desenhos, } \\
\text { corte e colagem levando } \\
\text { em consideração datas } \\
\text { comemorativas e outras } \\
\text { temáticas }\end{array}$ & $\begin{array}{l}\text { Este tipo de atividade é ótima para o desenvolvimento de concursos tanto na } \\
\text { área de pintura, confecção de gravuras como também no desenvolvimento da } \\
\text { escrita de textos. }\end{array}$ \\
\hline
\end{tabular}




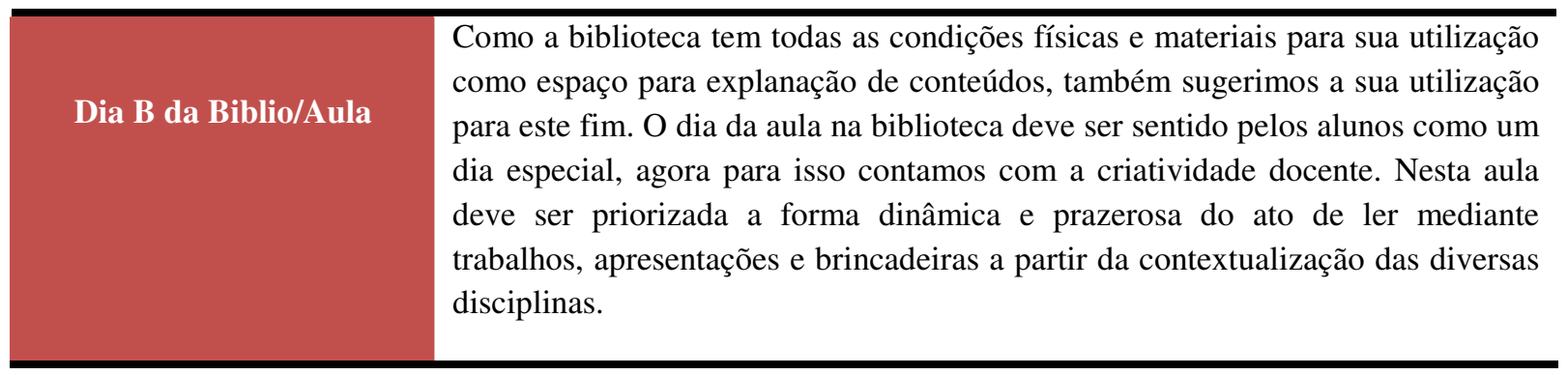

Fonte: Elaboração dos autores.

\section{Atividades - Eixo Composicional}

Este aspecto mobilizou pouco dos nossos esforços porque a nosso ver só necessitava de algumas aquisições como, por exemplo, de mobiliário que se manifestava insatisfatoriamente diante da demanda de alunos no desenvolvimento das atividades e a reorganização do espaço em si. Estes aspectos serão demonstrados por fotografia onde visualmente, o leitor terá uma visão mais ampla do que estamos discutindo.

Fotografia 1: Sem a Intervenção

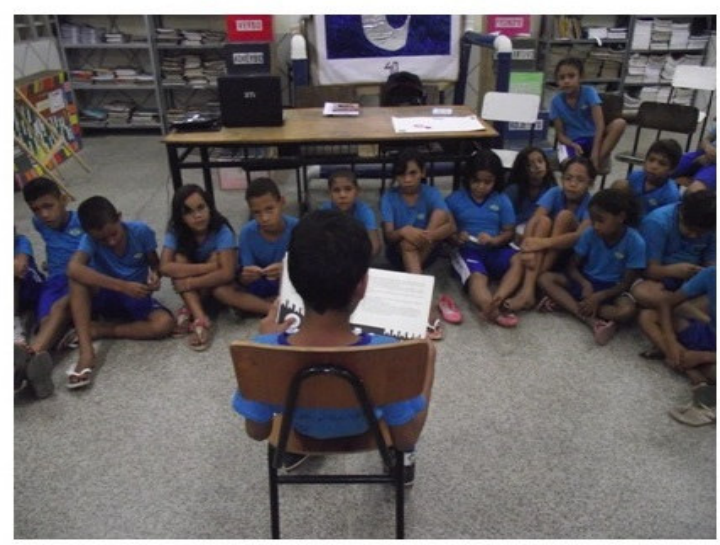

Fotografia 2: Após a Intervenção

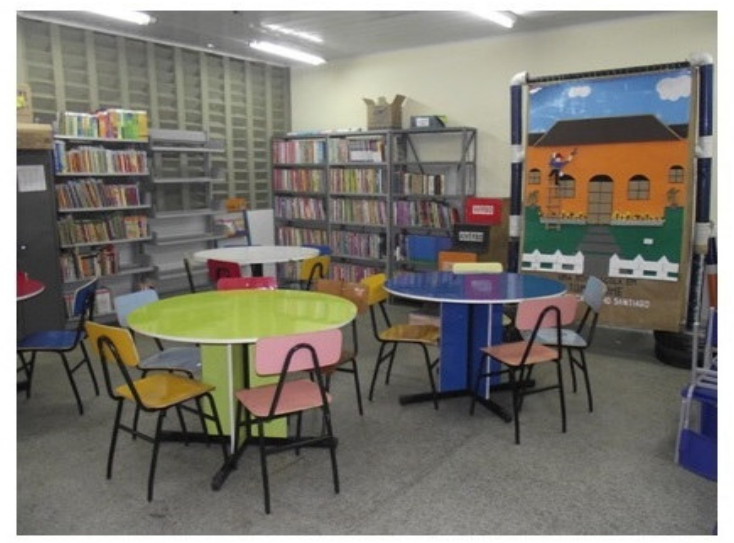

Foto: Acervo pessoal dos pesquisadores.

A fotografia 1 respalda o que colocamos para a direção da escola, ou seja, a necessidade de compra de alguns materiais e aquisição de mobiliário, uma vez que em atividades em lócus, muitos alunos ficavam de maneira desconfortável no ambiente. Ao fundo também podemos imaginar como estava o acervo, empilhados e sem nenhuma forma de sinalização. A fotografia 2 demonstra o ambiente da biblioteca escolar com o trabalho interventivo. 


\section{Considerações finais}

A proposta de descrever nossa experiência parte do princípio que nosso escrito se torna referência para profissionais, que assim como nós se deparam com realidades como a observada na intervenção e implicam-se em mudar. O que delineamos foi somente o inicio, ou seja, a base para formação de leitores e consolidar este ambiente ao projeto educativo da escola. Entretanto, o caminho para a concretização do que realmente almejamos que é a proficiência na leitura e, por conseguinte, a criticidade e reflexão que a sociedade que discutimos exige de nossos alunos, ainda é um caminho árduo frente à importância que gestores dão diante deste espaço em nosso país.

Demonstrar para professores e alunos os serviços e utilidade do ambiente de uma biblioteca escolar para o desenvolvimento e estímulo da formação leitora é uma possibilidade de acreditarmos na mudança, e é pensando nisso que sempre pautamos nossas ações, no sentido de corroborarmos com a melhoria seja individual ou coletiva de nossos alunos e da clientela das bibliotecas em que intervimos.

Reforçamos ainda a necessidade do redirecionamento do olhar dos responsáveis sobre estes espaços nas escolas públicas, uma vez que nossas experiências nos permitem afirmar que o mesmo é muito reduzido no ambiente escolar. Deixamos bem claro, que a biblioteca não deve ser confundida com depósito ou sala de aula. Sob o olhar do primeiro aspecto o enfoque é puramente tradicional, como a guardiã do saber e não movimentação das ideias, como já mencionado e sob o segundo, o sentido passa a ser puramente sob a mera obrigação curricular (Ir para aquele espaço somente para a internalização do saber sistematizado exigido pelo currículo). Biblioteca é descoberta, diversão, é deleite, é prazer, aspectos que vão além do tradicional ou mera obrigação.

Em relação à classificação em cores, embora receba algumas críticas principalmente no aspecto de coibir o conhecimento dos alunos das formas mais usuais no que tange a organização em bibliotecas. Nós acreditamos que ela é a que mais se adequa ao nível de maturidade do público alvo de bibliotecas escolares da qual fizemos nossa intervenção. Opinamos ainda com relação à mesma, que esta torna o entendimento da organização aos discentes do ensino fundamental menor o mais claro possível, aspecto este inviável nas classificações (Classificação Decimal de Dewey) e CDU (Classificação Decimal Universal) a faixa etária do estudo. 
Um aspecto que crermos ser o principal responsável para o insucesso das bibliotecas escolares é a ausência de um profissional especializado no espaço em discussão, embora reconheçamos os esforços de outros profissionais quando administram estas. O profissional que aqui evidenciamos tem por nomenclatura profissional bibliotecário. Só este profissional de formação superior, pela sua formação é capaz de dialogar suas competências técnicas (aspectos estes bem fragilizados na biblioteca que observamos no estudo) para o uso e organização dos materiais, ou seja, o acervo.

De nada adianta se a biblioteca é dotada de estrutura e acervo, se inexiste um profissional consciente das fragilidades e possibilidades desta. Desse modo, só implicará no que Fragoso (2013) nos apresenta, a utilização de forma arcaica do acervo.

Finalizamos esperançosos de que a realidade transformada se torne uma realidade diferenciada e que no futuro próximo, bons frutos sejam colhidos da nossa iniciativa enquanto pesquisadores e interventores e do custo público ofertado pela gestão da escola.

\section{Referências}

AGUIAR, N. C. Organização da informação em bibliotecas escolares: contribuições para a competência informacional. Bibl. Esc. em Rev., Ribeirão Preto, v. 1, n. 2, p. 31-44, 2012.

CASSERES, N. C. Como fazer conservação preventiva em arquivos e bibliotecas. São Paulo: Arquivo do Estado e Imprensa Oficial, 2000.

FRAGOSO, G. M. Biblioteca na escola. Presença Pedagógica, Belo Horizonte, v. 19, n. 110, p.10-16, mar./abr. 2013.

IFLA/UNESCO. Diretrizes para a biblioteca escolar. 2005. Disponível em: $<$ http://www.ifla.org/files/school-libraries-resource-centers/publications/schoollibraryguidelines/school-library-guidelines-pt_br.pdf_>. Acesso em: 17 jul. 2013.

NEVES, N. V.; RAMOS, F. B. O espaço da biblioteca escolar: análise das condições de mediações de leitura. In: CONGRESSO INTERNACIONAL DE FILOSOFIA E EDUCAÇÃO, 5., 2010, Caxias do Sul. Anais... Rio Grande do Sul, 2010. Disponível em:<http://www.ucs.br/ucs/tplcinfe/eventos/cinfe/artigos/artigos/arquivos/eixo_tematico8/O $\% 20$ espaco $\% 20 \mathrm{da} \% 20$ Biblioteca $\% 20$ Escolar_analise $\% 20$ das $\% 20$ condicoes $\% 20 \mathrm{de} \% 20 \mathrm{media}$ cao\%20de\%20leitura.pdf>. Acesso em: 22 set. 2014.

PINHEIRO, M. I. S. Classificação em cores: uma metodologia inovadora na organização das bibliotecas escolares do município de Rondonópolis-MT. Revista Digital de

Biblioteconomia e Ciência da Informação, Campinas, v. 7, n. 1, p. 163-179, jul./dez. 2009. 
SILVA, J. L. C.; SILVA, A. S. R. A mediação da informação como prática pedagógica no contexto da biblioteca escolar: algumas considerações. Bibl. Esc. em Rev., Ribeirão Preto, v. 1, n. 2, p. 1- 30, 2012.

VERGUEIRO, W. Seleção de materiais de informação: princípios e técnicas. Brasília: Brinquet de Lemos, 1995.

Seleção de materiais de informação: princípios e técnicas. 3. ed. Brasília: Briquet de Lemos, 2010.

VIANNA, H. M. Pesquisa em educação: a observação. Brasília: Plano, 2003. 